\title{
PENGUJIAN JUMLAH CEMARAN MIKROBA DALAM SIMPLISIA DAN EKSTRAK PEGAGAN SEBELUM DAN SETELAH PROSES PASTEURISASI SINAR GAMMA
}

\author{
DETERMINATION OF MICROBE CONTAMINANT \\ IN CENTELLA ASIATICA SIMPLISIA AND EXTRACT \\ BEFORE AND AFTER GAMMA-RAYS PASTEURIZATION
}

\author{
Eriawan Rismana*, Susi Kusumaningrum
}

Pusat Teknologi Farmasi dan Medika - BPPT

LAPTIAB - Gedung 611 - Kawasan Puspiptek - Serpong - Tangerang Selatan

*E-mail: eriawan.rismana@bppt.go.id

\begin{abstract}
ABSTRAK
Telah dilakukan pengujian cemaran mikroba dalam simplisia dan ekstrak pegagan (Centella asiatica) sebelum dan setelah proses pasteurisasi dengan sinar Gamma dalam beberapa dosis penyinaran. Proses penyinaran terhadap simplisia dan ekstrak pegagan mampu menurunkan secara signifikan jumlah cemaran mikroba yakni dari $>10^{4}$ menjadi < 10 -100 koloni. Pada dosis penyinaran sinar gamma 2,5 - 10,0 kGy mampu menurunkan cemaran mikroba pada ekstrak menjadi < 10 koloni. Hasil uji menunjukkan bahwa penyinaran sinar gamma pada ekstrak lebih efektif dibandingkan pada simplisia. Hasil analisis KLT menunjukkan bahwa proses penyinaran tidak merusak senyawa kimia aktif dalam ekstrak.
\end{abstract}

Kata Kunci : Ekstrak, Kandungan mikroba, pasteurisasi sinar Gamma, pegagan, simplisia,

\begin{abstract}
Determination of microbe content in the Centella asiatica simplisia and extract before and after pasteurization process by Gamma-rays with variation of dose has been evaluated. The radiation process into the simplisia and extract significantly decreased of microbe content from $>10^{4}$ to $<10-100$ colonies. For the various radiation dose at $2.5-10.0 \mathrm{kGy}$, the decreased microbe content in the extract to $<10$ colonies. The result showed that the radiation to extract was more effectively than to simplisia, in the decrease of microbe contaminant. The result of TLC analysis showed that the radiation was not affected to the active compound in extract.
\end{abstract}

Keyword : extract, microbe content, pasteurization Gamma-rays, Centella Asiatic, simplisia,

\section{PENDAHULUAN}

Indonesia selain kaya sumber daya hayati darat dan laut, juga kaya dengan pengetahuan masyarakat (indigenous knowledge) diantaranya dalam pembuatan jamu. Pengetahuan tersebut telah dikenal dan dimanfaatkan oleh masyarakat secara turun temurun untuk pemeliharaan dan peningkatan kesehatan, serta pencegahan dan pengobatan penyakit. Hampir setiap suku di Indonesia memiliki cara pengobatan dan jenis jamu sebagai warisan budaya masing-masing. Sebagian pengeta- 
huan masyarakat itu, telah digunakan oleh industri jamu dan obat tradisional untuk memproduksi jamu dengan menggunakan bahan simplisia kering. Sampai saat ini ternyata sekitar $80 \%$ populasi penduduk dunia di negara berkembang masih menggunakan pengobatan tradisional (diantaranya jamu) untuk menjaga kesehatan dan pemeliharaan kecantikan. Cina, India, Jepang, Indonesia, Malaysia, Korea merupakan beberapa negara yang menggunakan pengobatan tradisional sebagai salah satu pilihan dalam sistem pelayanan kesehatannya (KemenkesBPPT, 2010).

Simplisia dan ekstrak tanaman obat dapat dijadikan sebagai bahan aktif dan tambahan pada pembuatan sediaan jamu dan kosmetik. Saat ini, bahan herbal untuk sediaan kosmetik yang banyak digunakan adalah berupa simplisia tanaman dan sedikit yang menggunakan ekstrak apalagi bahan murni hasil isolasi/fraksinasi. Salah satu permasalahan yang ditemukan dalam penggunaan simplisia atau bahan ekstrak tanaman obat adalah masih belum terstandarisasinya bahan baku yang digunakan, sehingga tidak ada jaminan akan keseragaman kualitas dan khasiatnya. Diketahui bahwa kualitas tanaman obat sangat dipengaruhi oleh spesies, lokasi tumbuh, waktu pemanenan, serta pengolahan pasca panen.

Di sisi lain salah satu masalah yang sering ditemukan pada simplisia dan ekstrak yang diperoleh adalah masih tingginya cemaran mikroba di dalamnya. Cemaran ini timbul karena cara pengolahan dan budidaya yang masih dilakukan secara tradisional serta manual sehingga terkadang masih tercampur pengotor-pengotor organik dan anor-ganik lainnya. Untuk mengatasi masalah cemaran tersebut maka terhadap bahan baku simplisia atau ekstrak harus dilakukan proses penghilangan mikroba melalui proses pasteurisasi. Proses pasteurisasi dapat dilakukan dengan beberapa cara seperti menggunakan sinar UV, sinar IR, fumigasi memakai bahan kimia, pengeringan pada suhu tinggi, penambahan bahan pengawet dan penyinaran sinar Gamma (Winarno, dkk., 2010., Kadir, 2010., Nikham, dkk., 2011)

Dalam penelitian ini telah dilakukan proses pasteurisasi sinar Gamma terhadap simplisia dan ekstrak pegagan serta pengujian kandungan cemaran mikroba sebelum dan setelah proses pasteurisasi. Penelitian ini bertujuan untuk mengetahui dosis efektif dan efektivitas proses pasteurisasi terhadap simplisia dan ekstrak pegagan untuk menurunkan jumLah cemaran mikroba serta mengamati pengaruhnya terhadap kandungan senyawa kimia marker dari ekstrak pegagan.

\section{METODOLOGI}

\section{Proses pembuatan ekstrak}

Serbuk pegagan kering dima-serasi dengan pelarut campuran etanol : air dengan komposisi etanol 50\%, 70\% dan 90\% yang disertai dengan pengadukan. Maserat kemudian disaring dan filtrat yang diperoleh dipekatkan dengan rotary evaporator untuk mendapatkan ekstrak kental.

\section{Proses penyinaran}

Proses penyinaran terhadap simplisia kering dan ekstrak pegagan dilakukan di BATAN dengan dosis penyinaran yang bervariasi yakni dari 2,5 $10,0 \mathrm{kGy}$.

\section{Analisis kromatografi lapis tipis (KLT)}

Profil KLT ekstrak pegagan dianalisis secara kualitatif menggunakan metode kromatografi lapis tipis (KLT) dengan fase diam silika gel $\left(\mathrm{Si}_{60} \mathrm{~F}_{254}\right)$ dan fase gerak kloroform-metanol-air (65: 25 : 4, v/v), kemudian disemprot dengan pereaksi Liebermann-Burchard dan dipanaskan sampai bercak warna nampak.

\section{Penentuan cemaran mikroba angka lempeng total (ALT)}


Disiapkan 5 buah tabung yang telah diisi dengan $9 \mathrm{~mL}$ pengencer Pepton Dilution Fluid (PDF). Dari hasil homogenisasi pada penyiapan contoh dipipet pengenceran $10^{-1}$ sebanyak $1 \mathrm{~mL}$ ke dalam tabung yang berisi pengencer PDF pertama hingga diperoleh pengenceran $10^{-2}$ dan dikocok hingga homogen, selanjutnya untuk tabung-tabung berikutnya dibuat pengenceran hingga $10^{-6}$. Dari setiap pengenceran dipipet $1 \mathrm{~mL}$ ke dalam cawan Petri dan di buat duplo. Ke dalam tiap cawan Petri dituangkan 15-20 $\mathrm{mL}$ media PDA (Potato Dextrosa Agar) suhu $45{ }^{\circ} \mathrm{C}$ dan segera cawan Petri digoyang sehingga suspensi tersebar merata. Dibuat kontrol untuk menguji sterilisasi media dan pengencer. Setelah media memadat, cawan Petri diinkubasi pada suhu $35-37{ }^{\circ} \mathrm{C}$ selama $24-48$ jam dan kemudian dihitung jumlah koloni yang tumbuh.

\section{HASIL DAN PEMBAHASAN}

Simplisia pegagan (Centella asiatica) untuk penelitian ini didapatkan dari Lembang Jawa Barat (kode S1). Setelah dikeringkan simplisia kemudian dihaluskan dan diekstrak menggunakan metode maserasi. Hasil rendemen, kadar air, bentuk pasta dan warna ekstrak pegagan hasil proses ekstraksi menggunakan campuran etanol : air pada berbagai komposisi ditunjukkan pada Tabel 1.

Pada penelitian ini sampel pegagan yang akan dipasteurisasi dengan sinar Gamma adalah dalam bentuk simplisia dan ekstrak. Pemilihan bentuk simplisia dan ekstrak adalah untuk membandingkan efektivitas penyinaran terhadap kedua bahan tersebut. Proses ekstraksi menggunakan metode maserasi dilakukan menggunakan etanol karena didasarkan pada sifatnya yang mempunyai kemampuan cukup luas untuk memperoleh senyawa kimia yang bersifat non polar sampai polar, tidak toksik, aman digunakan, mudah diuapkan kembali, murah dan mudah didapatkan. Untuk mengetahui pelarut yang optimal dalam proses ekstraksi dan memperkecil biaya produksi ekstrak maka dilakukan juga ekstraksi dengan pelarut etanol yang dicampur dengan air dalam beberapa komposisi.

Tabel 1. Data hasil ekstraksi pegagan

\begin{tabular}{cccccc}
\hline No & Sampel Ekstrak & $\begin{array}{c}\text { Rendemen } \\
(\boldsymbol{\%})\end{array}$ & $\begin{array}{c}\text { Kadar air } \\
(\mathbf{\%})\end{array}$ & Bentuk & Warna \\
\hline 1 & Ekstrak S1 90\% & 18,63 & 8,50 & Pasta kental & Hijau kehitaman \\
2 & Ekstrak S1 70\% & 23,75 & 10,00 & Pasta kental & Hijau kecoklatan \\
3 & Ekstrak S1 50\% & 26,58 & 10,20 & Pasta kental & Hijau kecoklatan \\
\hline
\end{tabular}

Hasil menunjukkan bahwa proses ekstraksi menggunakan pelarut etanol 50\% memberikan rendemen hasil paling besar bila dibandingkan etanol $70 \%$ dan $90 \%$. Hal ini menunjukkan bahwa kandungan senyawa kimia dalam pegagan relatif mudah larut dalam air, karena senyawa aktifnya banyak yang mengandung gugus glukosida.

Untuk memenuhi persyaratan jumlah cemaran mikroba pada simplisia dan ekstrak yang akan digunakan sebagai bahan baku jamu atau kosmetik, maka umumnya pada bahan telah dilakukan uji angka lempeng total. Hasil uji cemaran mikroba dalam simplisia dan ekstrak pegagan ditunjukkan pada Tabel 2.

Hasil uji kandungan mikroba menunjukkan bahwa cemaran mikroba dalam simplisia dan ekstrak pegagan masih tinggi yakni berjumlah $>10^{3}-10^{4}$ koloni, sehingga belum memenuhi persyaratan Farmakope Indonesia (FI) (Farmakope Indonesia, 2014) dan Farmakope Herbal 
Indonesia (FHI) (Farmakope Herbal Indonesia, 2013) untuk digunakan sebagai bahan aktif dalam sediaan kosmetik atau jamu. Sebenarnya bila dilihat dari data hasil pengujian kandungan cemaran mikroba, proses ekstraksi mampu menurunkan jumlah kontaminasi seiring naiknya jumlah komposisi etanol dalam pelarutnya.

Tabel 2. Cemaran mikroba dalam simplisia dan ekstrak pegagan

\begin{tabular}{ccc}
\hline No & Sampel & Jumlah koloni (cfu/gram) \\
\hline 1 & Simplisia 1 (S1) & $>10^{4}$ \\
2 & Ekstrak S1 90\% & $>3 \times 10^{3}$ \\
3 & Ekstrak S1 70\% & $>10^{4}$ \\
4 & Ekstrak S1 50\% & $>10^{4}$ \\
\hline
\end{tabular}

Data Tabel 2 menunjukkan bahwa dalam ekstrak S1 70\% dan ekstrak S1 50\% kontaminan cemaran mikroba masih $>10^{4}$ sedangkan pada ekstrak S1 90\% cemaran sudah menurun menjadi $>10^{3}$. Dalam kondisi tersebut bila ekstrak atau simplisia tersebut digunakan langsung untuk sediaan kosmetik maka akan mengakibatkan kerusakan dan menurunkan kualitas pada produk sediaannya karena terjadi kontaminasi. Oleh karena itu untuk menurunkan jumlah cemaran mikroba tersebut tidak cukup hanya dengan menambahkan pelarut (etanol), tetapi masih diperlukan proses selanjutnya yaitu pasteurisasi.

Proses pasteurisasi telah dilakukan terhadap simplisia dan ekstrak pegagan dengan menggunakan sinar Gamma pada berbagai variasi dosis penyinaran yaitu dari 2,5 - 10,0 kGy. Tabel 3 menunjukkan jumlah cemaran mikroba dalam simplisia dan ekstrak pegagan sebelum dan setelah proses pasteurisasi pada beberapa dosis penyinaran.

Tabel 3. Hasil analisis cemaran mikroba dalam simplisia kering dan ekstrak pegagan sebelum dan setelah proses pasteurisasi

\begin{tabular}{ccccccc}
\hline \multirow{2}{*}{ No } & \multirow{2}{*}{ Sampel } & \multicolumn{5}{c}{ Dosis Radiasi } \\
\cline { 3 - 6 } & & sebelum & $\mathbf{2 , 5} \mathbf{~ k G y}$ & $\mathbf{5 ~ k G y}$ & $\mathbf{7 , 5} \mathbf{~ k G y}$ & $\mathbf{1 0 , 0} \mathbf{~ k G y}$ \\
\hline 1 & Simplisia S1 & $>10^{4}$ & $2 \times 10^{3}$ & $3 \times 10^{2}$ & $<100$ & $<10$ \\
& & koloni & koloni & koloni & koloni & koloni \\
\multirow{2}{*}{2} & \multirow{2}{*}{ Ekstrak S1 90\% } & $3 \times 10^{3}$ & $<10$ & $<10$ & $<10$ & $<10$ \\
& koloni & koloni & koloni & koloni & koloni \\
\hline
\end{tabular}

Dengan pertimbangan seperti kadar air dalam ekstrak, tingginya kadar senyawa marker, kemudahan pengambilan pelarut (etanol) pada proses rotavapor serta kandungan cemaran mikroba maka dalam penelitian ini ekstrak yang dipasteurisasi adalah ekstrak S1 90\%. Dari hasil uji cemaran mikroba pada Tabel $\mathbf{3}$ dapat dilihat bahwa setelah dilakukan pasteurisasi, cemaran bakteri yang terdapat dalam simplisia dan ekstrak pegagan berkurang secara signifikan sesuai dengan dosis radiasi yang digunakan. Jumlah cemaran dalam simplisia menurun masing - masing menjadi 2.000 koloni, 300 koloni, < 100 koloni dan $<10$ pada dosis penyinaran 2,5 kGy, $5 \mathrm{kGy}, 7,5 \mathrm{kGy}$ dan 10,0 kGy. Sedangkan cemaran pada ekstrak menurun hingga $<10$ koloni setelah penyinaran sinar Gamma pada dosis 2,5 - 10,0 kGy. Hasil pengujian ini menunjukkan bahwa proses pasteurisasi lebih efektif dilakukan pada ekstrak daripada simplisia, karena dosis penyinaran untuk menurunkan cemaran mikroba < 10 adalah mulai 2,5 kGy 
sedangkan pada simplisia adalah 10,0 kGy. Hal ini dimungkinkan karena sifat simplisia yang lebih meruah dibandingkan ekstrak, sehingga proses penyinaran menjadi kurang efektif

Proses pasteurisasi mungkin akan mengakibatkan perubahan pada kandungan senyawa kimia dalam ekstrak. Untuk mengetahui pengaruh penyinaran sinar Gamma terhadap kandungan senyawa asiatic acid dan asiaticoside alam ekstrak pegagan, maka telah dilakukan uji KLT. Kromatogram hasil uji KLT ditunjukkan pada Gambar 1.

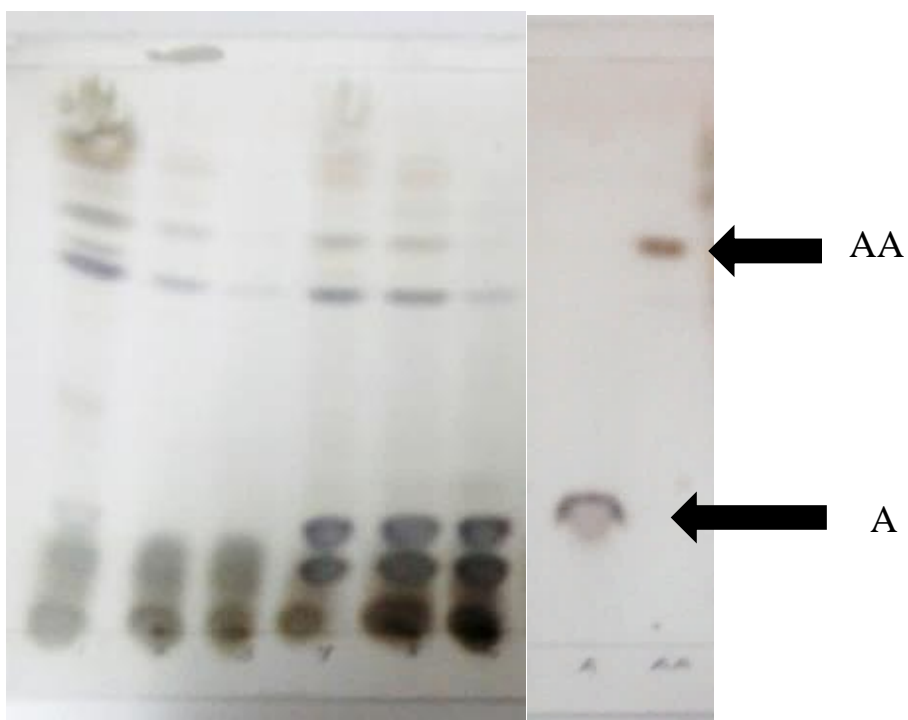

Gambar 1. Hasil analisa KLT : (kiri) ekstrak pegagan setelah penyinaran dan (kanan) senyawa standar asiatic acid (AA) dan asiaticoside (A)

Untuk mengetahui pengaruh penyinaran sinar Gamma terhadap kandungan senyawa kimia dalam ekstrak pegagan, maka telah dilakukan uji KLT terhadap ekstrak serta senyawa asiatic acid dan asiaticoside standar sebagai senyawa markernya. Hasil analisis KLT pada ekstrak menunjukkan kesamaan pola kromatogram. Selain itu kromatogram KLT juga menunjukkan adanya kandungan senyawa asiatic acid dan asiaticoside dalam ekstrak pegagan. Hasil tersebut menunjukkan bahwa proses pasteurisasi yang dilakukan tidak mempengaruhi senyawa yang ada dalam ekstrak.

\section{KESIMPULAN}

Proses pasteurisasi sinar Gamma dengan dosis penyinaran 2,5 kGy pada ekstrak pegagan mampu menurunkan kandungan cemaran mikroba hingga $<10$ koloni, sedangkan pada simplisia memerlukan dosis hingga 10,0 kGy . Dapat disimpulkan bahwa proses pasteurisasi lebih efektif dilakukan pada ekstrak dibandingkan simplisia dilihat dari dosis minimum penyinaran yang digunakan untuk menurunkan cemaran mikroba hingga $<10$ koloni.

Proses pasteurisasi pada ekstrak pegagan $90 \%$ etanol pada dosis penyinaran $2,5-10,0$ kGy tidak mengakibatkan kerusakan pada senyawa dalam ekstrak. Hal ini dicirikan identiknya pola kromatogram KLT dari ekstrak pegagan etanol $90 \%$ sebelum dan sesudah proses pasteurisasi serta adanya senyawa asiatic acid dan asiaticoside.

\section{DAFTAR PUSTAKA}

Kemenkes - BPPT, 2010, Studi kelayakan pembangunan unit produksi ekstrak terstandar.

Winarno, H., E. Katrin, W. Wisnurahadi dan S.R. Tamat, 2010, Dosis 
Pengujian Jumlah Cemaran Mikroba...(Eriawan Rismana dan Susi Kusumaningrum)

iradiasi optimum pada pengawetan simplisia kulit batang mahkotadewa (Phaleria macrocarpa (Scheff) Boerl.) sebagai antikanker, Jurnal Ilmiah Aplikasi Isotop dan Radiasi Vol. 6 No. 1 Juni, hal $1-16$.

Kadir, I, 2010, Pemanfaatan iradiasi untuk memperpanjang daya simpan jamur tiram putih (Pleurotus ostreatus) kering", Jurnal Ilmiah Aplikasi Isotop dan Radiasi, Vol. 6 No. 1 Juni , hal. 86 - 103 .
Nikham, R, Chosdu, E. Katrin, D.P. Rahayu, T.E. Basjir dan Susanto, 2011, Pemanfaatan Teknik Pasteurisasi Iradiasi Gamma untuk Menghasilkan Produk Kesehatan dari Tanaman Obat Jenis Zingiberaceae, Prosiding Seminar Ilmiah Hasil Penelitian Aplikasi Isotop dan Radiasi, Batan.

Farmakope Indonesia, Edisi V, 2014.

Farmakope Herbal Indonesia, Edisi I, 2013. 